\title{
THE IMPACT OF THE NEOLIBERAL TECHNOLOGICAL EPOCH AND COVID-19 ON THE DECOLONIZATION OF THE UNIVERSITY CURRICULUM
}

\section{O. Koopman}

SP-FET Department

Faculty of Education

Cape Peninsula University of Technology, Mowbray Campus

Cape Town, South Afrca

email: koopmano@cput.ac.za / http://orcid.org/0000-0002-1508-3967

\section{K. J. Koopman}

Department of Educational Studies

Faculty of Education

University of the Western Cape

Bellville, South Africa

email: kkoopman@uwc.ac.za / http://orcid.org/0000-0002-8079-8045

\section{ABSTRACT}

In this article we will argue that South Africa's capitalist neoliberal agenda for higher education, where the focus is on the shift from a knowledge economy to a digital economy, will choke the life of indigenous knowledge out of the university curriculum. To support this claim the article discusses, firstly, the impact of the core neoliberal ideals on the university curriculum landscape. Secondly, drawing on the scholarly work of Martin Heidegger and his anticipation of the spirit of the time in the technological epoch, the article shows how humans in this era will be viewed as a heap of fungible raw materials, resources, or standing reserve (Bestand) awaiting optimisation. In this technological age knowledge is subject to the demands of the market, where the focus will be exclusively on knowledge that has a utilitarian value in and impact on the technological epoch. $\mathrm{A}$ direct consequence of this is that little space will be provided for the inclusion of indigenous knowledge in the curriculum. We conclude by showing how the current Covid-19 pandemic dismissed the voices and disregarded the efforts of indigenous healers in the fight against the pandemic. All these developments illustrate government's power to impose its neoliberal agenda on the university that will ultimately lead to the detriment and neglect of indigenous knowledge.

Keywords: university, decolonization, curriculum, neoliberalism, technology

\section{INTRODUCTION}

Over the last three decades, despite the post-apartheid curriculum reforms that took place in the South African tertiary education sector, Western knowledge continues to dominate the 
curriculum landscape. This knowledge not only continues to objectify the world for students, but culminates in a regime of visibility where the very act of seeing finds its vanishing point in the subjectivity of the observer. In other words, Western knowledge not only defines what exists in the world around us, but also in a deterministic way displays the way things exist for us. In subjects like science and mathematics, this knowledge is taught religiously in university lecture theatres. At the same time, students are expected to respect these bare facts without question (and expected to know and repeat them in examinations), irrespective of how their personal lived world experiences, cultural dispositions, beliefs and values relate to these facts. Therefore, when students are taught these facts, they must be assimilated without dispute and any alternative worldview presuppositions or understanding must be suppressed. Khoo et al. (2020) refer to this form of education, dominated by Western forms of thinking, perspectives and concepts, while suppressing and dismissing alternative worldview presuppositions or understandings of the world imbedded in the lived world realities of the students, as epistemic injustice.

Le Grange et al. (2020) who investigated the progress made by university administrators and academics over the last five years in an attempt to decentre Western knowledge from the university curriculum, report that epistemic injustice is still held sway. Le Grange et al. (2020, 43) write "in all four cases [universities] the process of decentring Western knowledge and the insertion of indigenous and African knowledges is still largely absent ....”. If this is the case, and we believe similar trends exist in many other institutions across South Africa based on our engagements with our colleagues in many other universities, epistemic injustice will continue to form part of the structural inequalities that students will have to deal with. How to overcome epistemic injustice, Le Grange et al. (2020) argue, is one of the biggest challenges facing the modern-day South African university (and many other universities across the globe). Since universities are the key actors in both the production and dissemination of knowledge, the South African university landscape has been characterized by unprecedented mayhem and unrest since 2015 which at times turned out to be very violent, as students demanded, amongst many other things a decolonized curriculum as a form of epistemic justice (for full details, see Koopman 2019; Le Grange 2016; Postma 2016). This demand for a decolonized curriculum is explained in more detail later in the article, but Le Grange (2016) notes that it represents a decentring of dominant Western knowledge, perspectives and concepts in the university curriculum and a call for the inclusion of more local or African indigenous knowledge. According to Waghid (2018), over the last decade this call for the inclusion of more African indigenous knowledge in the university curriculum has become rather urgent as educators have become more vocal and critical of Western models, and in the process, it appears as if Western 
knowledge has lost its absolute monopoly in South African education. This is because educators have come to the realisation that the epistemologies, ontologies and methodologies that they teach their students in universities not only determine what they learn content-wise, but how they will act as future knowledge (re)producers (Khoo et al. 2020). A direct consequence of these anti-Western sentiments has been that the university sector finds itself swamped with rival claimants as to what constitutes worthwhile knowledge that speaks to the vibrant diversity on the African continent and the various ways of being, also referred to as African indigenous knowledge.

This brings us to the aim of this article, which is to argue that South Africa's capitalist neoliberal agenda for higher education, where the focus is on the shift from a knowledge economy to a digital economy, will choke the life of indigenous knowledge out of the university curriculum. To support this claim the article discusses, firstly, the impact of the core neoliberal ideals on the university curriculum landscape. Secondly, drawing on the scholarly work of Martin Heidegger and his anticipation of the spirit of the time in the technological epoch, the article will show how humans in the technological era will be viewed as a heap of fungible raw materials, resources, or standing reserve (Bestand) awaiting optimisation. The focus in this epoch will be on minimizing expense and maximizing profit. To do so, requires greater control over people to create a disciplined society in order to optimise them as resources. Furthermore, in the technological age knowledge is subject to the claims of the market, where the focus will be exclusively on knowledge that has a legitimate value in and impact on the technological epoch. From this perspective, we will argue that Western knowledge will take centre stage in the technological epoch and in the process, it will provide little room for the inclusion of indigenous knowledge in the university curricula. We conclude by showing how the current Covid-19 pandemic dismissed and disregarded the voices and efforts of indigenous healers in the fight against the pandemic. All these developments illustrate government's power to impose its neoliberal agenda on the university that will ultimately lead to the detriment and neglect of indigenous knowledge.

First, the article explains what is meant by Western knowledge before explaining African indigenous knowledge, which university students are fighting to have incorporated into the curriculum with greater urgency.

\section{WESTERN KNOWLEDGE AND INDIGENOUS KNOWLEDGE}

Over the years many advances have been made in Western knowledge. These advances resulted in the development of many theories about the world. These theories provided a particular view of reality and mode of being. Most of these advances in Western knowledge are based on 
principles of rationalism and empiricism propounded by philosophical scholars such as Hegel, Heidegger, Wittgenstein and the many other French and German scholars whose work cannot be ignored. All the knowledge generated over the many centuries by scholars in the West is what constitutes Western knowledge. According to Koopman (2018), for knowledge to be classified as "Western", it must be: (i) empirically verifiable; (ii) conform to certain ontological principles, theories and laws; and (iii) be experimentally consistent. In other words, Western knowledge is a combination of knowledge in the world (rationalism) but also knowledge of the world (empirical research generated through science). Most curricula with their disciplinespecific programmes in South African universities have been offered as the outcome of this knowledge, classified as facts, that originated in the West where the ideas of these scholars from the Global North are promoted as a superior form of knowledge of the world. This (western) knowledge is very different from the knowledge generated in other parts of the world such as Asia, Africa and various other sited, referred to as indigenous knowledge

Indigenous knowledge differs in its epistemologies, methodologies, logics, cognitive structures and its socio-economic context from Western knowledge. Over the years many different descriptions and explanations have been provided to explain what is meant by indigenous knowledge. One of the most robust summaries of indigenous knowledge is provided by Ogunniyi and Ogawa (2008), two scholars who made the study of indigenous knowledge in Africa and Asia, respectively, their life's work. They write:

"The term indigenous knowledge stands for an idea or system of thought peculiar to the so-called natives of a particular geographical location or socio-cultural environment. This implies that the knowledge has not been borrowed from another locality or culture or, if borrowed, it has become so assimilated into the new culture that it is difficult if not impossible to identify its original character or foreignness." (Ogunniyi and Ogawa 2008, 177).

Semali and Kincheloe (1999) similarly view indigenous knowledge as a mode of knowing and knowing that reflects the social and cultural rules and conventions of a specific location from which people develop their sense of identity. Their identities, as Semali and Kincheloe (1999, 3) put it, spring from "their relationship to their natural environment and how they organise that folk knowledge of flora, fauna, culture, 1 beliefs, and history to enhance their lives". For knowledge to be classified as indigenous, Maurial (1999) asserts, it must adhere to three main criteria: (i) the knowledge must be local - quotidian interactions in the territories of indigenous peoples between families, communities and indigenous and non-indigenous people in a specific locality; (ii) the knowledge must be holistic - no demarcation between disciplines as the knowledge is unified in a whole entity of worldviews; and (iii) the knowledge must adhere to principles of agrapha - a term that has its origin in Hispanic anthropology and means informal 
or undocumented knowledge. In other words, the knowledge must uphold the tradition of oral transfer from one generation in a family or community member to the next. In this way, the knowledge transfer encapsulates the holistic culture of family relations within and between people as well as with nature. These forms of knowledge are not documented theoretical knowledge, such as Western knowledge, that people can read and memorise from textbooks, but it is knowledge that is deeply ingrained in the human body. In other words, in an indigenous setting embodiment disregards the cerebrocentric and formalistic view of knowing, as in the Western tradition, and is more interested in the body's active engagement in the world. According to Varela, Thompson and Rosch (1991), such knowledge is an embodied-enactive form of thinking. The body not only knows and understand the place, the people and nature, but is harmoniously connected to place (locality). Turnbull (2000) puts it more succinctly as the knowledge that has a place. It is this knowledge specific to different indigenous communities in South Africa that students now want to incorporate into tertiary curricula. This brings us to the question of what is meant by "decolonising the university curriculum"?

\section{WHAT IS MEANT BY “DECOLONISATION”?}

Over the last 350 years under colonial and apartheid rule, many different Western figures settled here in South Africa. These figures used race and "otherness" to establish their dominance over the African populations. One mechanism of power that proved to be highly effective to control the African people was the colonization of knowledge. For example, Genuisz (2009) reports that to stop the spread and transfer of indigenous knowledge from one generation to the next, colonialists used psychological tactics advocating that indigenous knowledge is primitive and nonsensical. Furthermore, indigenous people were made to question the validity and credibility of their knowledge and to view it as wrong and inferior to Western knowledge. Under apartheid, we witnessed how apartheid ideologues such as the educational policies implemented by Hendrik Verwoerd that exorcised the rich traditions of African indigenous knowledge from curricula in both school and university programmes.

Therefore, when scholars like Le Grange (2016) describe the decolonization of the university curriculum as a means to "Africanise" its content, they refer to the return to the curriculum of the rich traditions and African knowledge, as a way of being, from the various tribes and cultures that have evolved for thousands of years. Scholars such as Etieyibo (2016) similarly argue for the return of the adoption and appropriation of experiences, beliefs, values and modes of being that reflects the African ways of life. Many scholars like Waghid (2014), Koopman (2018), Le Grange (2016) and Etieyibo (2016) point out that the decolonisation project should not follow a radical approach - the total exclusion of Western knowledge from 
the curriculum - but a more moderate approach - a curriculum that has enough space for both Western and indigenous knowledge which should be taught as complementary, instead of opposing bodies of knowledge.

Thus, in the context of this article, the decolonisation of the university curriculum should be viewed from two angles. On the one hand, it is primarily about the enchantment of the concrete in the curriculum - where units of knowledge are primarily embodied, incorporated and lived. On the other hand, it is about recognising the significance and value of indigenous knowledge and giving it equal status to Western knowledge in our university curriculum. This brings us to the question as to why it is proving to be so difficult for university administrators to allow indigenous knowledge into the university programmes? To address this, we need to shift the focus to the political landscape of neoliberalism to understand government's agenda for its citizens.

\section{A BRIEF DESCRIPTION OF NEOLIBERALISM AND ITS IMPACT ON EDUCATION IN SOUTH AFRICA}

Lyotard (1984) uses the notion of metanarratives to articulate the way practices and institutions are legitimated. According to Foucault (1978) institutions like schools and higher education institutions have been the primary systems to (re)programme people to accept certain ideologies to justify beliefs, practices and actions approved by the authorities. Foucault's (1978) critique of governments excess of power over the individual reveals how citizens, irrespective of their age and status, have been the subject of governmentality through domination and control. According to Lyotard (1984), in the postmodern era governments use the voice of reason in their education systems as a legitimizing grand narrative to control the minds of their citizens. This grand narrative of reason in the guise of individualism, privileges Western rational forms of knowing as the fount of all knowledge. This Western notion of rationality discounts all other alternative forms of knowledge (including indigenous knowledge) as the focus is mainly on economic prosperity. The notion of Western rationality also forms the foundation on which neoliberalism is built because it informs a not so concealed form of economic rationalism. In classical terms, neoliberalism has been construed as the assumption of homo economicus, which implicitly adopts the grand narrative that human beings in all their actions will act as selfinterested individuals. Peters $(2001,117)$ describes neoliberalism as:

\footnotetext{
"an entrenchment of a kind of rationalism that has, at least since World War II, come to occupy a dominant position with respect to a particular brand of economic science as a basis for policy, although assessments of its continued force differ considerably".
} 
Since the 1980s neoliberalism gained strong momentum in the West, which quickly spread to the rest of the world (for full detail see Steger and Roy 2010). Governments that adopted neoliberalism as an economic system had to radically reconstruct and align all aspects of society, with economic policies favouring mainly multinational organisations and foreign governments as manufacturing shifted abroad mainly for the sake of maximizing profits. Furthermore, governments that adopted neoliberalism had to (i) restructure the way the public sector functions, and (ii) move away from traditional ways of knowing to favour world trade as the mechanism that will enhance a developing world order.

The brunt of these neoliberal policies has been felt by every individual living in South Africa because the neoliberal agenda of government infiltrated every fibre of human existence, including its schools and university curricula. This is because, in a neoliberal system, political rationalism drives policy decision-making sectors (both public and private) which directly influences "whose knowledge" and "what knowledge" should be included in curricula in all educational institutions (schools and universities). Thus, in a neoliberal system the reasoning behind every decision-making process is motivated by "an extreme economic rationalism that views the market not only as a superior allocative mechanism for the distribution of scarce public resources but also as a morally superior form of political economy" (Peters 2001, 118). Simply put, the shift to marketization changed people's relationships and values towards stimulating the market. This means universities became more like a business which can be ascribed to the fact that universities were increasingly driven into entrepreneurial competition for external funding. For universities to thrive in this neoliberal economic system they have to privilege certain types of knowledge and the adoption of practices and procedures that would favour neoliberal governmentality. Seeing that Western knowledge in a neoliberal system is at the heart of the modern world, where digitisation and various forms of technological advancement constitute economic progress, it automatically renders African indigenous knowledge as politically unimportant. If this is the case, the questions that arise are: What is the purpose of universities in a neoliberal culture? What kind of knowledge will universities promote in the curricula in a university driven by neoliberal core ideals?

\section{THE PURPOSE OF THE UNIVERSITY AND KNOWLEDGE PROMOTION IN CURRICULA IN A NEOLIBERAL SYSTEM}

Koopman (2019) provides a succinct overview of the rise of neoliberalism in South Africa after 1994 and how policy-making in both the basic education and training sector as well as higher education and training were affected. He points out that, after fierce academic debate, the outcome in the official analysis of educational policy processes for South Africa was a shift 
from the vision of "Education for Liberation", a peoples-driven education system in the 1980s, to the adoption of neoliberal policies in the 1990s. This shift to an education system undergirded by neoliberal policies was done to gain entry to the global stage. According to Koopman (2019, $55)$ :
"Commensurate with this shift was the adoption of a framework that promoted procedures, regulations and domains of knowledge. ... The shift meant the adoption of practices and procedures that would favour neoliberal governmentality at the expense of core ethical African values and the development of a strong African identity."

Vally $(2020,1)$ shares similar sentiments about education in the age of neoliberalism when he writes:

\begin{abstract}
"The neoliberal approach to education centres on the commodification of education and the privileging of subjects, programmes and disciplines that largely benefit business at the expense of the arts, humanities and the social sciences. The "efficient" and "effective" delivery of education and other services are also left to market mechanisms such as privatisation for their resolution. This proposed "market solution" to our education crisis, even with state regulation, is less a case of a pragmatic attempt at resolving the problem than a case of ideological wishful thinking."
\end{abstract}

The shift to neoliberalism not only constructed the domestic political landscape with its focus on homo economicus, but it also had far-reaching consequences for the kinds of graduates that universities now had to produce. For universities, this meant that the focus shifted from social and national relevance to become innovation hothouses that put international capitalism in the driving seat (Barnett 2012). To do so, universities have been urged through government policies for higher education to adopt commercial models of knowledge, skills, curricula and management organisations. Some of these policy changes were evident in White Paper 1 on the Transformation of Higher Education (DHET 1997). For example, White Paper 1 on the Transformation of Higher Education (DHET 1997, 4) emphasises the restructuring of higher education to "meet the needs of an increasingly technological economy with the capacity to participate in a rapidly changing global context". This meant that universities must equip and empower graduates with the required knowledge, skills and capabilities that they need to use and implement in a super-complex world that is continually changing. This means universities move specific kinds of knowledge, "skills and capabilities" to the fore while foundational knowledge such as indigenous knowledge and its associated skills are increasingly marginalized. These pressures from the top, that are supported by university management complement wider neoliberal strategies for reshaping society on the model of the market place.

The more recent White Paper for Post-School Education and Training (DHET 2013) states that research and innovation and new knowledge production must receive priority and should 
increase if South Africa wants to achieve its developmental goals. One of these goals, according to this document, is to sharpen and strengthen its innovation system to the level of international standards (DHET 2013, 34). The keyword here is "international standards", which shows that the university's purpose is laid out from the "top down" and from "outside in". According to the White Paper for Post-School Education and Training (DHET 2013), the two main objectives of the South African university are: (i) to provide students with high-level skills for the labour market; and (ii) to be dominant producers of new knowledge. These objectives are in line with the National Plan for Higher Education (DHET 2001), which describes the primary role of the university as (i) human resource development; (ii) high-level skills training; and (iii) the production, acquisition and application of new knowledge in line with international standards. This is because the primary purpose of the university is to drive innovation and economic growth, which forms the backbone of the neoliberal agenda. Little attention is afforded to the importance and inclusion of indigenous knowledge in the university curricula.

In his 2019 State of the Nation Address the President of South Africa, Cyril Ramaphosa, gave the inclusion of indigenous knowledge in our curricula yet another blow when he announced the government's new vision for education. That vision is that universities must now prepare students for the fourth industrial revolution (4IR). Our aim is not to discuss in detail what the 4IR is about, so for full details, see Schwab (2016). In short 4IR, or as Schwab (2016) describes it the machine age refers to a new raft of disruptive technologies such as robotics, artificial intelligence, digital computing, 3D printing, amongst various other technologies and innovations that will soon hit all mainstream industries across the globe. Clearly, in such a system, little space will be left for the inclusion of indigenous knowledge, as the focus will be on knowledge valuable to the industry. According to Brynjolfsson and McAfee (2011), this is because the 4IR is a highly advanced technological revolution and thus will require knowledge that performs to show that it will have an impact on the world. For example, it is envisaged that everything in the manufacturing process will be digitised to bring greater productivity. For this revolution to materialise, a highly-skilled, technologically adept and innovative workforce is required. So, it is fair to ask what the role of indigenous knowledge will be in the technological age. This is an important question to raise if the universities in the 4IR will be interested primarily in knowledge that performs and will have a legitimate impact subject to the claims of the market. According to Lyotard (1984), the future technological age will bring with it a sense of newness, where knowledge will have no definite form, no conditions and no limits. This newness can be conceived as the illumination afforded by knowledge through its power over the world. In other words, universities are expected to bring this newness to their students in the form of knowledge that will assist them to fit in with the broader purposes of the 4IR. All 
these new developments in higher education show that African indigenous knowledge is politically unimportant to universities because of the government's new vision for education, that is in schools and universities. This implies that the focus is mainly on Western knowledge as a form of rationalism to give material form to the neoliberal agenda that the government has for its universities and graduates. This raises yet another question, that is what type of graduate must universities produce to function effectively in the technological age. This question specifically refers to the knowledge, thinking and cultural disposition that universities need to imprint in order for students to function effectively in the market place. To answer this question, we shift our attention to the scholarly work of Heidegger and his notion of "enframing" to anticipate government's plans for its graduates.

\section{HEIDEGGER'S ANTICIPATION OF THE TECHNOLOGICAL EPOCH}

Although Heidegger had no engagement with any of the modern technological tools and software programmes, he was one of the first philosophers, amongst the many twenty-firstcentury philosophical scholars, to write about technology and the impact it might have on modern civilisation. According to Belu (2017), his early writings opened the door for other scholars to philosophise about technology in modern society. Belu points out that Heidegger's philosophical writings on technology can be more broadly construed as reflecting the spirit of the times - from the German "Zeitgeist" - rather than addressing the modern conceptualisation of technology with all the various mobile devices and applications. She writes:

"His references to various modern technologies - windmills, air planes, cars, the lumber industry, the press, radio and TV, clinics, artificial insemination, the human resources department, the mechanized agricultural industry, concentration camps, hydrogen and atom bombs - are introduced and quickly passed over in favour of reflections on what he calls the essence (das Wesen) of technology" (Belu 2017, 8).

Heidegger's central ideas on the essence of technology and its impact on modern societies are captured in his famous essay titled "The Question Concerning Technology" published in 1954. In this essay he is more concerned with how the technological epoch will lead to more surveillance and control over people, with the aim of creating more order amongst people to drive greater efficiency to generate more profits. This brings us to the question: How will the world - behaviour, action and thinking - of the individual change in the technological epoch?

In Martin Heidegger's (1967) magnus opus Being and Time, the essence of human existence is viewed on the basis of his notion of Dasein. When translated from the German as "Sein" (being) and " $D a$ " (there/here), it is evident that the focus of our existence is not so much 
on how people think or what they believe, but on how they act and cope in the world within a particular context ( $D a$-there/here). It is in the process of "being" or "acting" in the world that a person's thoughts are made explicit. According to Heidegger (1967), Dasein has a particular discourse and structure which assumes knowledge as a way of being. In his later works, Heidegger's (1977) philosophy shifted to the field of "technology" as a mode of existence without any reference to "Dasein". He explored the notion of technology in his post-World War II essays on technology as follows:

“... this context is historicised so that any particular intentional arc or relationship between human existence and the world is always already circumscribed by a historical framework such as the technological one. Thus, for any set of norms or worlds to be revealed, other norms or worlds must be concealed. These norms vary, but the revealing-concealing structure of being itself within which these variable norms occur is invariable. The enframing is one such variant 'upon this overall invariant structure' of being and as such it necessarily conceals other variants." (Heidegger 1977, 2).

Although Heidegger does not conceive of technology as the modern day technologically advanced tools and processes, he views existence in the technological epoch as a time in which people will subscribe to particular behaviours and actions in the world. Hence, he coined the phrase das Ge-stell, which, in translation, means enframing (Belu 2017). According to Heidegger, enframing denotes a cultural imprint or a mode of revealing a specific attitude of modern civilisations. More specifically, it (enframing) is a representation mainly of how people will treat each other and the world primarily as a resource. He lucidly describes what he means by this when he writes how the people will be reduced to a "heap of fungible raw materials, resources, or standing reserve (Bestand) awaiting optimisation" (Belu 2017, 3). Heidegger predicted that the final goal of all human behaviour and action is predicated on the idea of pushing maximum profit with minimum expense, while at the same time gaining control and optimising people as resources.

Heidegger's anticipation of humanity in the digital age has all the signs and structure of a more severe form of neoliberalism that views the human subject as a tool to be used to drive the core ideals of multinational corporations which are primarily focused on profits. Furthermore, Heidegger's mental map of the technological epoch also has a lot in common with Schwab's $(2016,1)$ (architect of the 4IR) presentation at the economic summit in Davos, when he said:

"We stand on the brink of a technological revolution that will fundamentally alter the way we live, work, and relate to one another. In its scale, scope, and complexity, the transformation will be unlike anything humankind has experienced before. We do not yet know just how it will unfold, but one thing is clear: the response to it must be integrated and comprehensive, involving all 
stakeholders of the global polity, from the public and private sectors to academia and civil society."

Although Schwab is unclear about what the world will look like when the 4IR is in full swing, like Heidegger, he is confident that human relations will not be same as a consequence of the impact of technology. Schwab is not only confident that technology will transform the way people think and act, but also about the optimisation of production, management and governance. This brings us back to the question of whether or not there will be space for indigenous knowledge in the university curriculum.

Epistemologically, for universities to survive, they will have to be at the forefront of knowledge production and innovation. Heidegger's anticipation of enframing as a way life speaks to Lyotard's (1984) notion of performativity, which has more to do with seeing the individual student as an object that has value based on having a legitimate impact. Here impact refers to the value the individual brings to industry and the economic and technological value of the knowledge and skills he or she holds.

This means that university curricula will be the critical driver of government's neoliberal agenda, which is to maximise profits. In other words, the university as the driver of the technological epoch has a particular kind of individual in mind, one who subscribes to a particular culture. The main point we want to make here is that higher education is no longer about the social good, but essentially a political process of convergence that brings together certain knowledges and skills with a particular technologization of the self. The core of this convergence is primarily found in the discourse of neoliberalism which shapes the discourse and directions of all educational institutions, and the way curricula and knowledge are structured. Over the last two decades we have witnessed how students, amongst many others, are already viewed as raw materials in need of crafting in a market-driven knowledge economy to meet the needs of global capitalism. The neoliberal agenda has taken control of the university which revolves around the commodification of knowledge, and that relegates mathematics and science above human lived experience. In other words, if the vision for universities is to prepare students for the 4IR, little space will be provided for the decolonisation of university curriculum because politically it does not reflect the vision of the government for the future of education. The current Covid-19 pandemic has illustrated what kind of knowledge governments across the world privileges. Specifically, in South Africa where the voices and contributions made by indigenous healers were marginalised. Does this mean that universities of the future will pay less attention to indigenous knowledge? Next, we discuss the impact of Covid-19 on the university landscape and whether or not it has given the decolonisation of the curriculum project its final blow. 


\section{THE IMPACT OF COVID-19 ON INDIGENOUS KNOWLEDGE}

Over the last few months in the fight against Covid-19 we have witnessed how the government of South Africa marginalised the voices of its traditional healers and with it dismissed the potential contributions that African indigenous herbal remedies could make. Lesego Makgatho $(2020,1)$ from the Independent Times wrote "traditional healers lamented how they and their patients had been left out of national plans to help fight the pandemic". According to Makgatho, one of the biggest challenges facing our local indigenous healers is the Medicines and Related Substance Act 101 of 1965 which does not recognise traditional medication. Consequently, according to this act, it suggested that patients should rather use complementary medicine, that is drinking Western medicine in conjunction with indigenous herbal remedies.

Traditional healers in Madagascar, in their fight against Covid-19, developed an "organic herbal tea" called Covid-Organics produced from the Artemisia plant, which contains an active ingredient used to treat malaria. According to the traditional healers this remedy could produce results in seven days, but the product was not well received by the international community (Baker 2020). When the President of Madagascar arranged a press briefing to promote CovidOrganics, his advocacy of this untested cure sparked great consternation as he was rebuked by medical researchers in the West, many in the medical fraternity in Africa, and the United Nations World Health Organisation. According to Makgatho (2020), the response of Dr Tedros Adhanom Ghebreyesus, head of the World Health Organisation, in public was to reiterate that there are no shortcuts to finding a medical cure in the fight against this pandemic. According to the WHO Africa $(2020,1)$ :

\footnotetext{
"African governments through their Ministers of Health adopted a resolution urging Member States to produce evidence on the safety, efficacy and quality of traditional medicine at the Fiftieth Session of the WHO Regional Committee for Africa in 2000. Countries also agreed to undertake relevant research and require national medicines regulatory agencies to approve medicines in line with international standards, which include the product following a strict research protocol and undergoing tests and clinical trials."
}

Simply put, the WHO stated in no uncertain terms that it will not support any medicine (in this case a herbal remedy) that has not undergone clinical trials. The WHO $(2020,1)$ further issued the following media statement made by the President of Madagascar:

\footnotetext{
"Caution must be taken against misinformation ... many plants and substances are being proposed without the minimum requirements and evidence of quality, safety and efficiency. The use of such products can put people in danger, giving a false sense of security and distracting them from hand washing and physical distancing which are cardinal in Covid-19 prevention."
} 
Although we are aware of that the Covid-Organic herbal remedy cannot be considered as a cure for Covid-19, it is the nature of indigenous knowledge, that is not subject to scientific testing, that was condemned. This is implied in the responses by the WHO in the above statement, that African indigenous medicine should convert their knowledge from a cultural and spiritual epistemology to a scientifically valid epistemology. Furthermore, it shows the pressure of the current neoliberal world system to pour scorn on alternative knowledges (indigenous activities) of which the benefits may lie in the social, cultural or even religious dimensions. Epistemologically, it shows that the fields of knowledge (and the generation thereof) are not evenly placed to demonstrate the value of African indigenous knowledge. Beyond the epistemological field, it also shows that Western knowledge is far more superior than indigenous knowledge because of its scientific rigour and safety. Therefore, to ensure the survival of universities which is to generate income, securing their public and international reputations and to have their qualifications recognised internationally. We think it is fair to ask the following question, in light of the developments with the pushback received by the indigenous communities during this time in the fight of Covid-19: If indigenous knowledge must now withstand international scrutiny by experts in the field for it to be classified as valid and acceptable knowledge, does this mark the end of the inclusion of indigenous knowledge in our university curricula?

\section{CONCLUSION}

This article has shown that the "decolonisation of the university curriculum" runs far deeper than an academic challenge and leans more towards a political challenge. We have argued that the survival of the university in a neoliberal culture must privilege specific knowledge that will spawn new understandings for students to function optimally in the technological epoch. We have shown how this shift to the technological epoch brings challenges to universities regarding the inclusion of indigenous knowledges in the university curricula. As we are speeding towards the 4IR we have seen over the last three decades how knowledge has grown so rapidly that we are starting to lose touch with the physical world. This new normal or newness that technology has brought is in line with Popper's (1972) anticipation of a new world referred to as World Three, imbedded in objective knowledge. This view of a shift to a new world, that Popper (1972) refers to as world three, is not entirely wrong given the anticipated shift from a knowledge economy to a digital economy where the focus will be exclusively on knowledge that has a utilitarian value in and impact on the technological epoch. During the current Covid19 pandemic, as researchers across the world are struggling to find a cure for the disease, we 
have witnessed that it is knowledge that stands up to the highest standard of scientific scrutiny that will stand the test of time. Furthermore, as discussed in this article, regarding the new vision for education in South African schools and universities that now have to shift to the 4IR, to develop a highly advanced technological revolution, will require knowledge that performs to show its impact on the world. All these things are evidence that universities favour objective knowledge, as Popper proposed. Therefore, we think it's fair to ask if there is still a place for indigenous knowledge in the university curriculum. This question we ask, in light of the global movements shifting to this unknown new world, where physical touch and human connectedness are slowly disappearing. All these developments are creating obstacles for the future of African indigenous knowledge and might constrain its inclusion in university curricula.

\section{REFERENCES}

Baker, Aryn. 2020. "Could it work as a cure? Maybe. A herbal remedy for coronavirus is a hit in Africa, but experts have their doubts." Times. http://www.google.co.za/amp/s/time.com/5840148/ coronavirus-cure-covid-madagascar/\%3famp=tru (Accessed March 2020).

Barnett, Ronald. 2012. The future university: Ideas and possibilities. New York: Routledge.

Belu, Dana. 2017. Heidegger, reproductive technology and the motherless age. New York: Palgrave Macmillan.

Brynjolfsson, Erik, and Andrew McAfee. 2011. Race against the machine: How the digital revolution is accelerating innovation, driving productivity, and irreversibly transforming employment and the economy. Lexington, MA: Digital Frontier Press.

Department of Higher Education and Training. 1997. White Paper 1 on the Transformation of Higher Education. Pretoria: DHET

Department of Higher Education and Training. 2001. National Development Plan. Pretoria: DHET

Department of Higher Education and Training. 2013. White Paper for Post-School Education. Pretoria: DHET.

DHET see Department of Higher Education and Training.

Etieyibo, Edwin. 2016. "Why ought the philosophy curriculum in universities in Africa be Africanised?" South African Journal of Philosophy 35(4): 404-417.

Foucault, Michel. 1978. "Governmentality”. In The Foucault effect: Studies in governmentality, ed G. Burgell, C. Gordon, and P Milner. Memel Hempstead: Harvester Wheatsheaf.

Geniusz, Wendy. 2009. Our knowledge is not primitive: Decolonising botanical Anishinaabe teaching. New York: Routledge.

Heidegger, Martin. 1967. Being and time. Translated by J. Macquarrie and E. Robinson. London: SCM Press.

Heidegger, Martin. 1977. The question concerning technology and other essays. Transalated by W. Lovitt. New York: Harper \& Row Publishers.

Khoo, Su-ming, Witold Mucha, Christina Pesch, and Cori Wielenga. 2020. "Epistemic (in)justice and decolonisation in higher education: Experiences of cross-site teaching project." Acta Academica 52(1): 54-75.

Koopman, Oscar. 2019. "Is the decolonisation of the South African university curriculum possible in a neoliberal culture?" Alternation 24: 48-69. 
Koopman, Oscar. 2018. "Towards decolonising teaching strategies: How to domesticate and infuse Western knowledge with indigenous knowledge." Journal of Education 74: 102-116.

Le Grange, Lesley. 2016. "Decolonising the university curriculum." South African Journal of Higher Education 30(2): 1-12.

Le Grange, Lesley, Petro du Preez, Labby Ramrathan, and Sylvan Blignaut. 2020. "Decolonising the university curriculum or decolonial washing? A multiple case study." Journal of Education 80: 25-49.

Lyotard, Jean-Francois. 1984. The postmodern condition: A report on knowledge. Manchester: Manchester University Press.

Makgatho, Lesego. 2020. "Our herbs can help with Covid-19, say traditional healers." Times independent. https://www.iol.co.za/sundayindependent/news/our-herbs-can-help-with-covid-19say-traditional-healers-47793844 (Accessed August 2020)

Maurial, Mahia. 1999. "Indigenous knowledge and schooling: A continuing between conflict and dialogue." In What is indigenous knowledge: Voices from the academy, ed L. Semali, and J. Kincheloe. New York: Farmer Press.

Ogunniyi, Meshach, and Masakata Ogawa. 2008. The prospects and challenges of training South African and Japanese educators to enact an indigenised science curriculum. South African Journal of Higher Education 22(1): 175-190.

Peters, Michael. 2001. Poststructuralism, Marxism and Neoliberalism: Between theory and politics. Oxford: Rowman and Littlefield Publishers.

Popper, Karl. 1972. Objective knowledge: An evolutionary approach. Oxford University Press.

Postma, Dirk. 2016. "The ethics of becoming in a pedagogy for social justice." South African Journal of Higher Education 30(3): 310-328.

Schwab, Klaus. 2016. The fourth industrial revolution, Davos 2016. http://www.weforum.org/ agenda/2016/01/the-fourth-industrial-revolution-what-it-means-and-how-to-respond (Accessed 13 March 2018).

Semali, Ladislaus, and Joe Kincheloe. 1999. Introduction: "What is indigenous knowledge and why should we study it." In What is indigenous knowledge: Voices from the academy, ed L. Semali, and J. Kincheloe. New York: Farmer Press.

Steger, Manfred, and Ravi Roy. 2010. Neoliberalism: A very short introduction. London: Oxford Press.

Turnbull, David. 2000. Masons, tricksters and cartographers: Comparative studies in the sociology of scientific and indigenous knowledge. New York: Routledge

Vally, Salim. 2020. "Between the vision of yesterday and the reality of today: Forging a pedagogy of possibility." Education as Change 24: 1-24.

Varela, Francisco, Evan Thompson, and Eleanor Rosch. 1991. The embodied mind: Cognitive science and human experience. Cambridge, MA: The MIT Press.

Waghid, Yusef. 2014. Towards an African philosophy of education. New York: Routledge.

Waghid, Yusef. 2018. Towards an African university of critique. Paper presented at the $2^{\text {nd }}$ Philosophy and Theory of Higher Education Conference. Hosted by the University of Sussex, London. 7- 9 September 2018.

World Health Organisation Africa. 2020. "WHO supports scientifically-proven traditional medicine." https://www.afro.who.int/news/who-supports-scientifically-proven-traditional-medicine (Accessed August 2020).

WHO see World Health Organisation. 